\title{
Validated RP-HPLC and HPTLC methods for simultaneous estimation of febuxostat and diclofenac sodium in pharmaceutical dosage form
}

\author{
Ponnuveetil Gopi Sunitha a and Kaliappan Ilango b,*
}

a Department of Pharmaceutical Chemistry, College of Pharmacy, Madras Medical College, Chennai, 600003, Tamil Nadu, India

b Department of Pharmaceutical Chemistry, Sri Ramaswamy Memorial College of Pharmacy, Sri Ramaswamy Memorial University, Kattankulathur, 603203, Tamil Nadu, India

*Corresponding author at: Department of Pharmaceutical Chemistry, Sri Ramaswamy Memorial College of Pharmacy, Sri Ramaswamy Memorial University, Kattankulathur, 603203, Tamil Nadu, India.

Tel.: +91.944.4144120. Fax: +91.044.27432342.E-mail address: ilangok67@gmail.com (K. Ilango).

\section{COMMUNICATION INFORMATION}

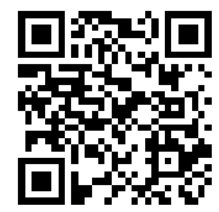

DOI: $10.5155 /$ eurjchem.5.3.545-549.1066

Received: 05 April 2014

Received in revised form: 01 May 2014

Accepted: 01 May 2014

Online: 30 September 2014

\section{KEYWORDS}

Tablet

HPTLC

RP-HPLC

Validation

Diclofenac

Febuxostat

\section{Introduction}

Febuxostat (FEB) is chemically known as 2-(3-cyano-4isobutoxyphenyl)-4-methyl-1,3-thiazole-5-carboxylic acid [1]. The chemical structure of febuxostat is shown in Figure 1. Febuxostat is a non-purine xanthine oxidase inhibitor used in the treatment of hyperuricaemia with chronic gout [2]. Diclofenac (DIC) is chemically 2-(2,6-dichloranilino) phenyl acetic acid [1]. The chemical structure of diclofenac is shown in Figure 2. It is a nonsteroidal anti-inflammatory drug (NSAID) taken or applied to reduce inflammation and as an analgesic for reducing pain in certain conditions [2]. Literature review revealed that spectrophotometric method [3], HPLC methods [4-7] and stability indicating studies [8-12] have been reported for estimation of febuxostat and HPLC $[13,14]$ and spectrophotometric [15-17] methods have been reported for diclofenac alone. Further a validated HPLC method [18] for simultaneous estimation of febuxostat and diclofenac potassium in bulk and tablet dosage form on $\mathrm{C}_{18},(250 \mathrm{~mm} \times 4.6$ $\mathrm{mm} \times 5 \mu \mathrm{m})$ column using acetonitrile:methanol:water (30:30:40, v:v:v; $\mathrm{pH}$ adjusted to 5.0 with TEA and $o$-phosphoric acid) as mobile phase and validated simultaneous equation and absorbance ratio methods $[19,20]$ for the simultaneous estimation of febuxostat and diclofenac in tablet dosage form have been reported.

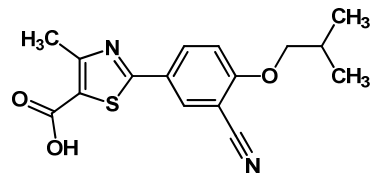

Figure 1. Structure of febuxostat.<smiles>O=C(O)Cc1ccccc1Nc1c(Cl)cccc1Cl</smiles>

Figure 2. Structure of diclofenac.

In this work, a simple RP-HPLC method using methanol: $\mathrm{KH}_{2} \mathrm{PO}_{4}(0.02 \mathrm{M})(70: 30, v: v)$ as mobile phase and HPTLC method using toluene:methanol in the ratio of $7: 3(v: v)$ as mobile phase have been reported. 
HPTLC is becoming a routine analysis technique due to advantages of low operating cost, high sample throughput, and need for minimum sample cleanup. The major advantage of HPTLC is that several samples can be run simultaneously using a small quantity of mobile phase unlike HPLC, thus lowering analysis time and cost per analysis.

\section{Experimental}

\subsection{Instrumentation}

The HPLC system (Jasco Corporation, Tokyo, Japan) consisted of dual Pump (Model: Jasco PU-2080 Plus and Jasco PU-2087 Plus Intelligent Prep.) along with manual injector sampler programmed at $20 \mu \mathrm{L}$ capacity per injection. The UV/ VIS (Model: Jasco UV 2075) detector was used. LC separations were performed on a Thermo Hypersil $\mathrm{C}_{18}$ column $(250 \mathrm{~mm} \times$ $4.6 \mathrm{~mm}$ i.d., $5 \mu \mathrm{m}$ particle size). Camag HPTLC system with Camag linomat IV automatic sample applicator, Camag TLC scanner III and Camag WinCATS software were used for HPTLC method. Saturation was done in Camag Twin-trough chamber $(20 \times 10 \mathrm{~cm})$. Merck plates coated with silicagel $60 \mathrm{~F}_{254}(250 \mu \mathrm{m}$ thickness) on aluminium sheets was used as stationary phase.

\subsection{Reagents and chemicals}

Working standards of pharmaceutical grade FEB and DIC were obtained as gift samples from Centaur Pharmaceuticals Ltd., Pune. The tablet XANFEB DSR containing $40 \mathrm{mg}$ FEB and $100 \mathrm{mg}$ DIC was procured from the local pharmacy. All the chemicals and reagents used were of HPLC grade obtained from Merck Ltd., Mumbai, India.

\subsection{Mobile phase}

The mobile phase used in HPLC was methanol: $\mathrm{KH}_{2} \mathrm{PO}_{4}$ $(0.02 \mathrm{M})(70: 30, v: v)$. The flow rate was set to $1.0 \mathrm{~mL} / \mathrm{min}$. In HPTLC, toluene:methanol in the ratio of 7:3 $(\mathrm{v}: \mathrm{v})$ was used as mobile phase.

\subsection{Preparation of standard stock solution}

Standard stock solution of FEB and DIC containing 100 $\mu \mathrm{g} / \mathrm{mL}$ and $1000 \mathrm{ppm}$ were prepared for HPLC and HPTLC methods, respectively. From the above stock solution, concentrations in the range of $2-12 \mu \mathrm{g} / \mathrm{mL}$ of FEB and $5-30$ $\mu \mathrm{g} / \mathrm{mL}$ of DIC for HPLC and $40-280 \mathrm{ng} / \mathrm{band}$ of FEB and 100$600 \mathrm{ng} / \mathrm{band}$ of DIC for HPTLC were prepared. The peak area for the different concentrations of FEB and DIC were recorded. The chromatogram in Figure 3 shows the retention time of FEB and DIC as 6.725 and 8.892 min, respectively, by HPLC method. The calibration curves were constructed between concentration against their respective peak area for FEB and DIC, respectively. Figure 4 shows the UV overlay spectrum of FEB and DIC and Figure 5 represents 3-D Chromatogram obtained in HPTLC study showing peaks of FEB and DIC in different concentrations. The densitogram of FEB and DIC is shown in Figure 6.

\subsection{Sample preparation}

For analysis of the tablet dosage form, twenty tablets (XANFEB DSR, Indoco Remedies Ltd.) containing $40 \mathrm{mg}$ of FEB and $100 \mathrm{mg}$ of DIC were weighed individually and their average weight was determined.

For HPLC method, the tablets were crushed to a fine powder and powder equivalent to the weight of $40 \mathrm{mg}$ of FEB and $100 \mathrm{mg}$ of DIC was transferred to a $100 \mathrm{~mL}$ volumetric flask and dissolved in about $30 \mathrm{~mL}$ of mobile phase. The solution was shaken for $5 \mathrm{~min}$ and then ultrasonicated for 15$20 \mathrm{~min}$ and filtered through $0.45 \mu \mathrm{m}$ Whatman filter paper. The residue was washed with mobile phase and the combined filtrate was made up to the mark with the same solvent. $1 \mathrm{~mL}$ of this solution was diluted to $100 \mathrm{~mL}$ solvent to get the final solution that consists of concentration of $4 \mu \mathrm{g} / \mathrm{mL}$ of FEB and $10 \mu \mathrm{g} / \mathrm{mL}$ of DIC. The solution $(20 \mu \mathrm{L})$ was then injected for quantitative analysis. The identities of both the compounds were established by comparing retention time of the sample solution with those of standard mixed solution.

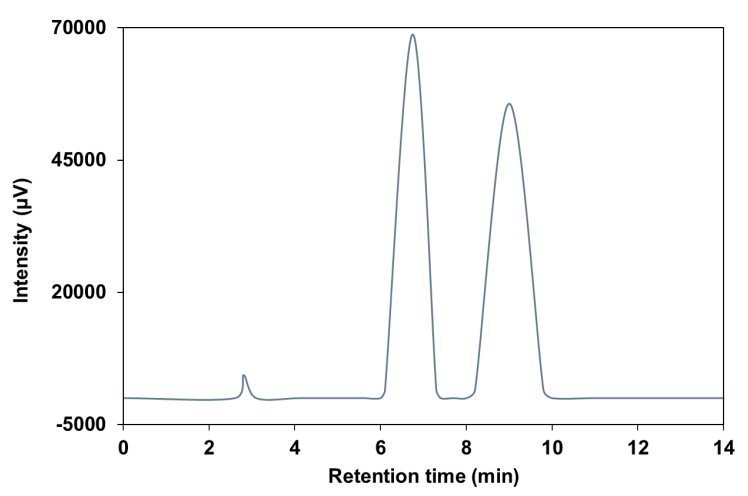

Figure 3. Chromatogram showing $\mathrm{R}_{\mathrm{t}}$ of FEB and DIC.

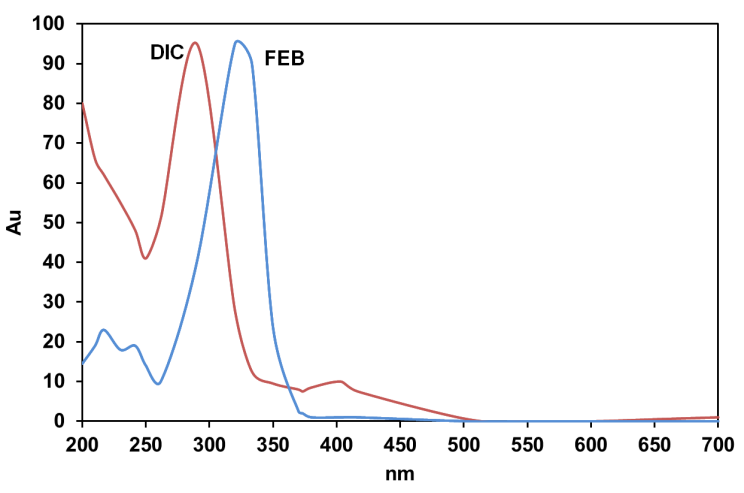

Figure 4. UV overlay of FEB and DIC.

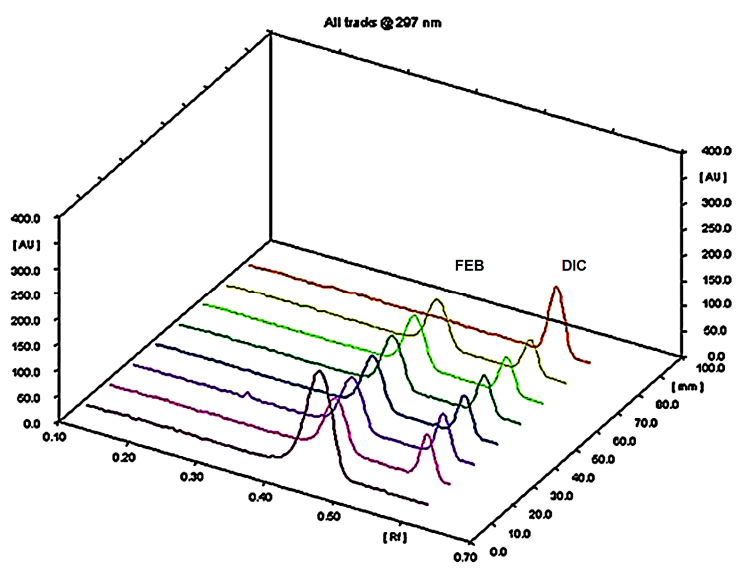

Figure 5. 3-D Chromatogram showing peaks of FEB and DIC in different concentrations at $297 \mathrm{~nm}$.

For HPTLC method, quantity equivalent to $40 \mathrm{mg}$ of FEB and $100 \mathrm{mg}$ of DIC was taken in $100 \mathrm{~mL}$ volumetric flask and dissolved in $40 \mathrm{~mL}$ methanol and the final volume was made up with the same solvent. The solution was filtered through 0.45 $\mu \mathrm{m}$ nylon syringe filter. 
Table 1. Analysis of the marketed formulation by HPLC and HPTLC methods *.

\begin{tabular}{|c|c|c|c|c|c|c|}
\hline \multirow[t]{2}{*}{$\overline{\text { Drug }}$} & \multicolumn{3}{|l|}{ HPLC } & \multicolumn{3}{|l|}{ HPTLC } \\
\hline & Amount taken, $\mu \mathrm{g} / \mathrm{mL}$ & Drug content (\%) \pm S.D. & \%RSD & Amount taken, ng/band & Drug content (\%) \pm S.D. & $\%$ RSD \\
\hline$\overline{\text { FEB }}$ & 4 & $99.821 \pm 0.081$ & 0.019 & 120 & $99.68 \pm 0.018$ & 0.158 \\
\hline DIC & 10 & $100.190 \pm 0.154$ & 0.055 & 300 & $99.21 \pm 0.134$ & 0.183 \\
\hline
\end{tabular}

Table 2. Linear regression data for the calibration curves by HPLC and HPTLC methods a.

\begin{tabular}{|c|c|c|c|c|}
\hline \multirow[t]{2}{*}{ Parameter } & \multicolumn{2}{|l|}{ HPLC } & \multicolumn{2}{|l|}{ HPTLC } \\
\hline & FEB & DIC & FEB & DIC \\
\hline Linearity range & $2-12 \mu \mathrm{g} / \mathrm{mL}$ & $5-30 \mu \mathrm{g} / \mathrm{mL}$ & $40-280 \mathrm{ng} /$ band & $100-600 \mathrm{ng} / \mathrm{band}$ \\
\hline$r^{2}$ & 0.9997 & 0.9997 & 0.9989 & 0.9999 \\
\hline Slope \pm standard error & $33170 \pm 268.3$ & $44490 \pm 385.2$ & $26.76 \pm 0.4507$ & $14.01 \pm 0.0663$ \\
\hline Intercept \pm standard error & $3093 \pm 20.89$ & $1098 \pm 75.00$ & $209.47 \pm 70.22$ & $46.289 \pm 25.84$ \\
\hline Confidence limit of slope ${ }^{b}$ & 32430 to 33920 & 43420 to 45550 & $25.50 \pm 28.01$ & $13.82 \pm 14.19$ \\
\hline Confidence limit of intercept $b$ & -2708 to 8893 & -19720 to 21920 & $14.55 \pm 404.4$ & $-25.43 \pm 118.0$ \\
\hline Sy.x ${ }^{c}$ & 2244 & 8057 & 75.42 & 27.75 \\
\hline$p$ value d & $<0.0001$ & $<0.0001$ & $<0.0001$ & $<0.0001$ \\
\hline
\end{tabular}

$p$ valued $\quad<0.0001$

b $95 \%$ confidence intervals.

c Standard deviation of residuals from line.

d $p$ value is $<0.0001$, considered highly significant.

Table 3. Accuracy studies for the determination of FEB and DIC by HPLC and HPTLC methods *.

\begin{tabular}{|c|c|c|c|c|c|}
\hline \multirow[t]{2}{*}{ Drug } & \multicolumn{5}{|l|}{ HPLC } \\
\hline & Amount added (\%) & Theoretical content $(\mu \mathrm{g} / \mathrm{mL})$ & Measured conc. \pm SD & Recovery (\%) & \% R.S.D \\
\hline \multirow[t]{3}{*}{$\overline{\text { FEB }}$} & 80 & 4.8 & $4.85 \pm 0.06$ & 96.29 & 1.212 \\
\hline & 100 & 6 & $6.05 \pm 0.02$ & 100.8 & 0.399 \\
\hline & 120 & 7.2 & $7.25 \pm 0.04$ & 100.75 & 0.687 \\
\hline \multirow[t]{3}{*}{ DIC } & 80 & 12 & $11.94 \pm 0.01$ & 99.5 & 0.153 \\
\hline & 100 & 15 & $14.94 \pm 0.08$ & 99.6 & 0.084 \\
\hline & 120 & 18 & $18.17 \pm 0.09$ & 100.94 & 0.094 \\
\hline \multirow[t]{2}{*}{ Drug } & HPTLC & & & & \\
\hline & Amount added (ng) & Total amount (ng) & Amount recovered (ng) & Recovery (\%) & \% R.S.D \\
\hline \multirow[t]{3}{*}{$\overline{\mathrm{FEB}}$} & 20 & 60 & 58.58 & 97.64 & 1.01 \\
\hline & 40 & 80 & 81.52 & 101.9 & 0.98 \\
\hline & 60 & 100 & 97.73 & 97.73 & 1.15 \\
\hline \multirow[t]{3}{*}{$\overline{\mathrm{DIC}}$} & 50 & 150 & 150.68 & 100.45 & 1.16 \\
\hline & 100 & 200 & 197.86 & 98.93 & 0.48 \\
\hline & 150 & 250 & 247.45 & 98.98 & 1.37 \\
\hline
\end{tabular}

From the resultant solution $1 \mathrm{~mL}$ was diluted to $10 \mathrm{~mL}$ which contains 40 and 100 ppm of FEB and DIC respectively. 3 $\mu \mathrm{L}$ volume was spotted for six times to achieve a final concentration of $120 \mathrm{ng} / \mathrm{band}$ for FEB and $300 \mathrm{ng} / \mathrm{band}$ for DIC. The plate was developed in the previously described chromatographic conditions and the peak area of the spots was measured at $297 \mathrm{~nm}$. The results of analysis of marketed formulation by HPLC and HPTLC methods are reported in Table 1.

\subsection{Validation}

The validation of an analytical method verifies that the characteristics of the method satisfy the requirements of the application domain. The proposed method was validated in the light of ICH Guidelines [21]. The developed method was validated for linearity, accuracy, precision, repeatability, selectivity and specificity study as per ICH guidelines. All the validation studies were carried out by replicate injection of the sample and standard solutions.

\subsubsection{Linearity}

Linear relationship was observed in concentrations ranging from $2-12 \mu \mathrm{g} / \mathrm{mL}$ for FEB and $5-30 \mu \mathrm{g} / \mathrm{mL}$ for DIC in HPLC and 40-280 ng/band for FEB and 100-600 ng/band for DIC in HPTLC. From the data obtained correlation coefficient, yintercept and slope were calculated to provide mathematical estimates of the degree of linearity (Table 2).

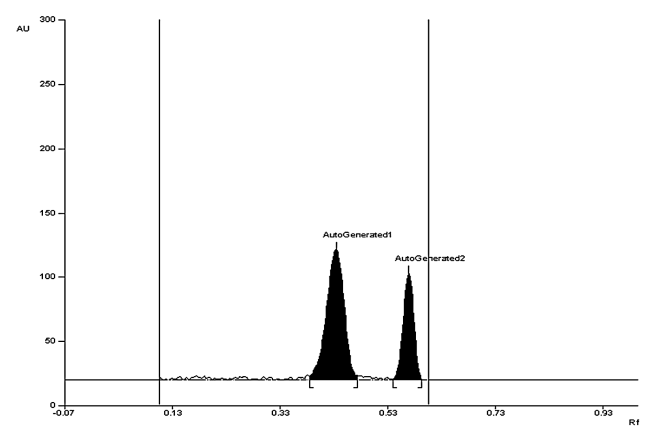

Figure 6. Densitogram of FEB (0.48) and DIC (0.60) standard.

\subsubsection{Accuracy}

Accuracy of the developed methods was carried out by adding known amount of each drug corresponding to three concentration levels; 80,100 and $120 \%$ of the label claim in HPLC and 50, 100 and $150 \%$ of the label claim in HPTLC. The accuracy was expressed as the percentage of analytes recovered by the assay methods. The results of percentage recovery are shown in Table 3.

\subsubsection{Precision}

Precision was studied by repeatability and intermediate precision studies. 
Table 4. Results of Precision study by HPLC and HPTLC methods*

\begin{tabular}{|c|c|c|c|c|c|c|c|c|}
\hline \multirow[t]{3}{*}{ Drug } & \multicolumn{5}{|l|}{ HPLC } & \multicolumn{3}{|l|}{ HPTLC } \\
\hline & \multirow{2}{*}{$\begin{array}{l}\text { Drug conc. } \\
(\mu \mathrm{g} / \mathrm{mL})\end{array}$} & \multirow{2}{*}{$\begin{array}{l}\text { Repeatability } \\
\text { Found conc. } \pm \text { S.D. }\end{array}$} & \multirow[b]{2}{*}{$\%$ RSD } & \multicolumn{2}{|c|}{ Intermediate precision } & \multirow{2}{*}{$\begin{array}{l}\text { Drug conc. } \\
\text { (ng/band) }\end{array}$} & \multirow{2}{*}{$\begin{array}{l}\text { Intraday precision } \\
\% \text { RSD }\end{array}$} & \multirow{2}{*}{$\begin{array}{l}\text { Interday precision } \\
\% \text { RSD }\end{array}$} \\
\hline & & & & Found conc. \pm S.D. & $\%$ RSD & & & \\
\hline \multirow[t]{3}{*}{$\overline{\text { FEB }}$} & 2 & $1.9394 \pm 0.0012$ & 0.065 & $1.9312 \pm 0.0122$ & 0.632 & 40 & 1.42 & 1.55 \\
\hline & 6 & $6.0677 \pm 0.0008$ & 0.013 & $6.0816 \pm 0.0501$ & 0.824 & 120 & 1.11 & 1.48 \\
\hline & 12 & $11.917 \pm 0.0043$ & 0.036 & $11.8529 \pm 0.1297$ & 1.094 & 240 & 1.71 & 1.71 \\
\hline \multirow[t]{3}{*}{$\overline{\mathrm{DIC}}$} & 5 & $5.019 \pm 0.0307$ & 0.612 & $5.1356 \pm 0.0985$ & 1.919 & 100 & 1.53 & 1.002 \\
\hline & 15 & $14.898 \pm 0.0192$ & 0.128 & $14.826 \pm 0.1184$ & 0.798 & 300 & 0.121 & 1.53 \\
\hline & 30 & $30.7689 \pm 0.1954$ & 0.650 & $29.9605 \pm 0.4040$ & 1.348 & 600 & 0.434 & 0.625 \\
\hline
\end{tabular}

Table 5. Limit of detection(LOD) and limit of quantitation(LOQ) in HPLC and HPTLC methods.

\begin{tabular}{lllll}
\hline Parameter & HPLC & HPTLC & DIC \\
\cline { 2 - 5 } & FEB & DIC & FEB & $0.24 \mathrm{ng} / \mathrm{band}$ \\
\hline LOD & $0.32 \mu \mathrm{g} / \mathrm{mL}$ & $1.13 \mu \mathrm{g} / \mathrm{mL}$ & $0.70 \mathrm{ng} / \mathrm{band}$ & $0.13 \mathrm{ng} / \mathrm{band}$ \\
LOQ & $0.98 \mu \mathrm{g} / \mathrm{mL}$ & $2.87 \mu \mathrm{g} / \mathrm{mL}$ & & $0.37 \mathrm{ng} / \mathrm{band}$ \\
\hline
\end{tabular}

Table 6. Robustness evaluation a of the method by HPLC $(n=6)$.

\begin{tabular}{|c|c|c|c|c|c|}
\hline \multirow[t]{2}{*}{ Factor } & \multirow[t]{2}{*}{ Level } & \multicolumn{2}{|c|}{ Retention time $\left(t_{R}\right)$} & \multicolumn{2}{|c|}{ Asymmetry (T) } \\
\hline & & FEB & DIC & FEB & DIC \\
\hline \multicolumn{6}{|l|}{ A: Flow Rate ( $\mathrm{mL} / \mathrm{min})$} \\
\hline 0.9 & -1 & 6.712 & 8.687 & 1.02 & 1.15 \\
\hline 1.0 & 0 & 6.725 & 8.892 & 1.01 & 1.17 \\
\hline 1.1 & +1 & 6.613 & 8.788 & 1.01 & 1.16 \\
\hline \multicolumn{6}{|c|}{ B: Percentage of methanol in the mobile phase (v:v) } \\
\hline 71 & -1 & 6.712 & 8.824 & 1.33 & 1.23 \\
\hline 70 & 0 & 6.725 & 8.892 & 1.31 & 1.22 \\
\hline 72 & +1 & 6.798 & 8.878 & 1.29 & 1.21 \\
\hline \multicolumn{6}{|c|}{ C: Columns from different manufacturers } \\
\hline Hypersil C18 column & & 6.725 & 8.892 & 1.31 & 1.22 \\
\hline HiQ-Sil ${ }^{T M}$ HS C18 column & & 6.798 & 8.811 & 1.32 & 1.23 \\
\hline
\end{tabular}

a Average of three concentrations 2,6 and $12 \mu \mathrm{g} / \mathrm{mL}$ for FEB, 5, 15 and $30 \mu \mathrm{g} / \mathrm{mL}$ for DIC.

Table 7. Robustness evaluation of the method by HPTLC ( $n=6)$.

\section{Parameter}

Mobile phase composition $( \pm 0.1 \mathrm{~mL})$

Amount of mobile phase $( \pm 5 \%)$

Time from application to development $(+10 \mathrm{~min})$

Time from development to scanning (+10 min)

The results are reported in terms of relative percentage standard deviation (\% RSD) as in Table 4.

\subsubsection{Limit of detection (LOD), and limit of quantification (LOQ)}

The lowest amount of the analyte in the sample which can be detected and the lowest amount of analyte which can be quantitatively determined were studied and, LOD and LOQ values are reported in Table 5 .

\subsubsection{Robustness}

The robustness of the methods was determined by subjecting the methods to slight changes in the chromatographic conditions. It was observed that there was no marked change in the chromatogram which demonstrated that the methods developed are robust (Table 6 and 7).

\subsubsection{Selectivity}

The selectivity was checked by injecting the solution of both the drugs into the HPLC system and it was observed that two sharp peaks of FEB and DIC having resolution of 2.511 were obtained at retention time of 6.725 and $8.892 \mathrm{~min}$, respectively. In HPTLC, the $R_{\mathrm{f}}$ values of FEB and DIC were found to be 0.48 and 0.60 , respectively. It was observed that the excipients did not interfere with the retention time and $\mathrm{R}_{\mathrm{f}}$ values of the drugs. So, the methods developed for this combined dosage form are said to be selective.

\subsubsection{Specificity}

Specificity of the method was assessed by comparing the chromatograms obtained for standard drugs with the chromatogram obtained for tablet solution. The retention time and $R_{f}$ values of standard drugs and the drugs in sample solution were same, so the methods are specific. The results of system suitability parameters in HPLC are shown in Table 8.

\subsubsection{Stability of analytical solution in HPLC}

Stability of sample solution was established by storage of sample solution at ambient temperature for 48 hours. FEB and DIC sample solution was re-analyzed after 24 and $48 \mathrm{hr}$ time intervals and assay value was determined and compared against fresh sample. Sample solution did not show any appreciable change in assay value when stored at ambient temperature up to $48 \mathrm{hr}$. It was found that the percentage labeled amounts of FEB at 0,24 and $48 \mathrm{hr}$ were $99.8,100.1$ and 100.5 , respectively and the percentage labeled amounts of DIC were $100.1,99.9$ and 100.3 , respectively.

\section{Results and discussion}

Column chemistry, solvent type, solvent strength, detection wavelength and flow rate were varied to determine the chromatographic conditions giving the best separation. The mobile phase conditions were optimized so that the components were free from the interference of solvent and excipients. 
Table 8. System suitability parameters in HPLC

\begin{tabular}{llll}
\hline Parameter & FEB & DIC & Reference values \\
\hline Theoretical plates (N) & 2216.17 & 2074 & N $>2000$ \\
Peak asymmetry (T) & 1.01 & 1.17 & $T \leq 2$ \\
Capacity factor (K') & 1.06 & 1.61 & $1<\mathrm{K}^{\prime}<10$ \\
HETP $(\mathrm{H})$ a & 0.11 & 0.12 & A \\
Selectivity $(\alpha)$ b & 1.39 & & Rs $\geq 2$ \\
Resolution (Rs) & 2.511 & & \\
\hline
\end{tabular}

Resolution (Rs) b

b With respect to previous peak.

Mobile phase and flow rate selection was based on peak parameters like height, area, tailing, theoretical plates, capacity factor, resolution and run time. In HPTLC, the effect of chamber saturation time on peak shapes, development pattern and $\mathrm{R}_{\mathrm{f}}$ value were studied. The chamber saturation time was fixed as $30 \mathrm{~min}$ as the $R_{\mathrm{f}}$ value and resolution were satisfactory for FEB and DIC. Plate equilibration time was fixed as $20 \mathrm{~min}$ as the plates developed after $20 \mathrm{~min}$ of saturation showed good precision and reproducibility of peak area of drugs. The composition of solvent constituting the mobile phase was varied in order to study its effect on resolution of drugs. The analytes should have distinct retention time and $R_{\mathrm{f}}$ values for good resolution. The best result was obtained by use of 70:30 ( $v: v$ ) ratio of methanol and $0.02 \mathrm{M} \mathrm{KH}_{2} \mathrm{PO}_{4}$ in HPLC and toluene:methanol in the ratio $(7: 3, v: v)$ in HPTLC. Under the optimum chromatographic conditions, the retention time obtained for FEB and DIC were 6.725 and $8.892 \mathrm{~min}$, respectively, in HPLC method and $\mathrm{R}_{\mathrm{f}}$ values for FEB and DIC were found to be 0.48 and 0.60 , respectively, in HPTLC method. The values obtained for the validation parameters show that, the chromatographic conditions are appropriate for separation and determination of the compounds.

\section{Conclusion}

A new RP HPLC method and HPTLC method have been developed for simultaneous analysis of Febuxostat and Diclofenac in combined dosage form. The developed methods were found to be linear, accurate, reproducible, repeatable, precise, selective and specific proving the reliability of the methods. The recovery studies indicate that there was no interference of excipients. The proposed methods may be successfully applied to routine analysis of samples containing Febuxostat and Diclofenac.

\section{Acknowledgements}

We are thankful to Centaur Pharmaceuticals Ltd, Pune for providing us the gift samples of febuxostat and diclofenac sodium.

\section{References}

[1]. Sweetman, S. C., Martindale: The Complete Drug Reference, 37th edition, Pharmaceutical Press, London, 2011.

[2]. O'Neil, M. J. The Merck Index, 14 ${ }^{\text {th }}$ edition, Merck Research Laboratories, 2011.

[3]. Bagga, P.; Salman, M.; Siddiqui, H. H.; Ansari, M. A.; Mehmood, T.; Singh, K. Int. J. Pharm. Sci. Res. 2011, 2(10), 2655-2659.

[4]. Kumar, R. J.; Kumar, B. R.; Patnaik, V. V.; Kumar, A. Int. Res. J. Pharm. 2012, 3(11), 205-208.

[5]. Nasare, M.; Harshini, S.; Kumar, A. M.; Diwan, V.P. Int. J. Pharm. Chem. Biol. Sci. 2012, 3(1), 137-142.

[6]. Sudhir, M. S.; Venkata, N. R.; Nadendla, R. R. Int. J. Pharm. Tech. Res. 2012, 4(4), 974-984.

[7]. Krishnareddy, Y.; Sundaraganapathy, A.; Thangadurai, S. A.; Hemanth, G.; Jambulingam, M.; Niraimathi, V. J. Pharm. Res. 2012, 5(7), 39003908.

[8]. Rajyalakshmi, C.; Benjamin, T.; Babu, C. R. Int. J. Res. Pharm. Biomed. Sci. 2013, 4(1), 138-144.

[9]. Patel, S. D.; Sharma, N.; Patel, C. M.; Patel, N. B.; Shrivatsav, S. P.; Sanyal, M. J. Adv. Pharm. Sci. Tech. 2013, 1(1), 37-41.

[10]. Mandle, D. S.; Burade, K. B. Int. J. Pharm. Biol. Res. 2013, 4(1), 1-10.
[11]. Mollati, S.; Rao, V.; Jagaveera, K. N. Am. J. Pharm. Res. 2013, 3(2), 406422.

[12]. Wang, H.; Deng, P.; Chen, X.; Guo, L.; Zhong, D. Biomed. Chromatogr. 2013, 27(1), 34-38.

[13]. Prakash, K.; Patro, S. S.; Shanta, K. K.; Rao, M. E. B. Acta Cienc. Indica. 2004, 135, 135-138.

[14]. Ahmed, N. R. Iraqi Nat. J. Chem. 2011, 44, 467-473.

[15]. Mandava, V.; Rao, B.; Reddy, B. C. K.; Rao, T. S.; Prasanthi, V. Rasayan J. Chem. 2009, 2, 488-490.

[16]. Barry, A.; Mahmood, M.; Hamezh, J. M. J. Kerbala Univ. 2009, 7, 310 316.

[17]. Akshaya, A. K.; Joshi, G. K.; Mishra, P. Ind. J. Pharm. Sci. 1992, 54, 4446.

[18]. Baria, H. S.; Patil, P.; Modi, H.; Patel, P.; Patel, S.; Chandalia, K. Inv. Rap. Pharm. Anal. Qual. Ass. 2013, 3, 627-631.

[19]. Mothalia, C. P.; Prajapati, K. R.; Parmar, R. R.; Shah, V. N.; Shah, D. A Int. J. Pharm. Sci. 2013, 4(3), 268-278

[20]. Priya, M. H. Int. J. Pharm. Bio. Sci. 2013, 4(3), 134-138.

[21]. ICH Q2 (R1), Validation of Analytical Procedures: Text and Methodology, The International Federation of Pharmaceutical Manufacturers \& Associations, Geneva, Switzerland, 2005. 